\title{
Physiological Response of Bermudagrass Grown in Soil Amendments during Drought Stress
}

\author{
Grady L. Miller ${ }^{1}$ \\ Department of Environmental Horticulture, University of Florida, Gainesville, \\ FL 32611-0670
}

Additional index words. Cynodon dactylon x C. transvaalensis, transpiration, extractable water, zeolite, porous ceramic, diatomaceous earth, peat, drought

\begin{abstract}
The effects of several soil amendments, following a single filling of core aerification holes, on growth and transpiration of 'Tifdwarf' bermudagrass [Cynodon dactylon $(\mathrm{L}$. Pers. $x$ C. transvaalensis Burtt Davy] were examined during drought stress. Soil amendments had variable effects on turf quality. In general, turf grown in ZeoPro ${ }^{\circledR}$ - and Profile ${ }^{\circledR}$-amended sand had the highest quality. Data indicated that the evaluated soil amendments have the potential to influence soil water content, ultimately influencing transpirational response to drought stress. Amended sand contained 1\% to $16 \%$ more transpirable water compared with non-amended sand. Turfgrass grown in Axis ${ }^{\circledR}$ - and Isolite $\AA$-amended sand required 0.4 to 1.4 days longer to reach the endpoint (transpiration rate of drought stressed plants $<\mathbf{1 2 \%}$ of well-watered plants) during a period of rapid water depletion. Data from this study suggest that the total volume these amendments occupied in the root zone, following a single filling of core aerification holes in sand, may positively influence soil moisture status, resulting in an increase in drought avoidance.
\end{abstract}

Modern golf greens are constructed using root-zone media consisting primarily of medium to coarse sand $(0.25-1.00 \mathrm{~mm})$. The highly permeable sands resist compaction and have adequate aeration, infiltration, and percolation, but poor nutrient and water retention. During construction and maintenance, golf green soils are often amended to improve resiliency and nutrient and water retention (Beard, 1973). Decomposed peat is the organic material most commonly used in rootzone modification. Although organic amendments increase water and nutrient retention, they decompose with time. Thus, an amendment is needed that will increase water- and nutrient-holding capacity while remaining stable over time. In general, plant transpiration responds to water deficits on the basis of the fraction of total extractable water in the root zone (Ritchie, 1980; Sinclair and Ludlow, 1986; Weisz et al., 1994). The point at which transpiration begins to decline relative to the fraction of transpirable soil water (FTSW) reflects the point at which stomata begin to close and photosynthesis begins to decline. The purpose of this research was to examine the effects of several soil amendments currently marketed for golf green use on transpiration of 'Tifdwarf' bermudagrass during drought stress and their influence on drought stress avoidance.

Received for publication 15 Mar. 1999. Accepted for publication 20 July 1999. Journal Paper no. R06708, Florida Agriculture Experiment Station. The cost of publishing this paper was defrayed in part by the payment of page charges. Under postal regulations, this paper therefore must be hereby marked advertisement solely to indicate this fact.

'E-mail: glmi@gnv.ifas.ufl.edu

\section{Materials and Methods}

Two greenhouse experiments were conducted at the Univ. of Florida Turfgrass Envirotron facility in Gainesville. Expt. 1 was established 18 Mar. and Expt. 2 on 5 June 1997. As a result, soil dehydration data for Expt. 1 were taken during a period of higher evapotranspiration demand for Expt. 1 than for Expt. 2. In both experiments, grass was established in pots $(178 \mathrm{~mm}$ wide at top, tapering to $145 \mathrm{~mm}$ at bottom and $160 \mathrm{~mm}$ deep). Pots receiving an amendment were filled with an equal volume and weight of U.S. Golf Association (USGA) specification sand and planted with 'Tifdwarf' bermudagrass at a sprigging rate of $11.4 \mathrm{~L} \cdot \mathrm{m}^{-2}$. Pots that were not to receive an amendment were filled with the corresponding soil treatment [USGA specification sand or native soil (Arredondo fine sand)] at an equal volume and established at the same time, using the same sprigging rate.

Overhead irrigation was used to allow bermudagrass to establish uniformly across all pots. Grasses were fertilized with full-strength Hoagland No. 2 basal solution (Sigma Chemical, St. Louis) following sprigging and then with $\mathrm{NH}_{4} \mathrm{NO}_{3}$ at $24 \mathrm{~kg} \cdot \mathrm{ha}{ }^{-1} \mathrm{~N}$ each week for 5 weeks to promote rapid establishment. Turf was clipped twice per week at $\approx 5$-mm cutting height during establishment. After allowing 6 weeks for establishment, amendment treatments were applied to the appropriate pots. Nine cores 20 -mm wide $\times 100$-mm deep on 50 -mm centers were removed from pots using hollow metal tines permanently attached to a thermoplastic sheet that was designed to fit over the pots consistently while providing the proper core depth. After cores were removed, amendments were back-filled into the holes using a funnel to prevent spillage outside the holes. This resulted in the amendment comprising $11 \%$ of the surface area and $8.5 \%$ of the total volume of the container. Amendment treatments included four clinoptilolite zeolite products [Ecolite ${ }^{\circledR}$ (Western Organics, Phoenix), EcoSand ${ }^{\circledR}$ (Zeo, Denver), EcoSand $X \AA$ (Zeo), and ZeoPro (Zeoponix, Louisville, Colo.], one diatomaceous earth [PSA ${ }^{\circledR}$ (Golf Ventures, Lakeland, Fla.)], one calcined diatomaceous earth [Axis (Agro Tech 2000, Norristown, Pa.)], three porous ceramics [Isolite (Davisson Golf, Baltimore), Profile (Profile LLC, Buffalo Grove, Ill.), Profile Fine ${ }^{\circledR}$ (Profile LLC)], and one material whose contents were undetermined [Greenschoice ${ }^{\circledR}$ (Premier Environmental Products, Houston)]. Treatments were replicated six times.

Following fill treatment applications, grasses were fertilized weekly with $\mathrm{NH}_{4} \mathrm{NO}_{3}$ at $12 \mathrm{~kg} \cdot \mathrm{ha}^{-1} \mathrm{~N}$ for 6 more weeks. Evaluations were made following regrowth of turf cover over filled aerification holes. Turf height was maintained at 5-7 $\mathrm{mm}$ above the soil line by clipping twice per week. Turf quality was evaluated 12 weeks after initial establishment of the two experiments ( 6 weeks after amendments were introduced) using a 1 to 10 rating scale, where $1=$ dead stand, $7=$ minimum acceptable level, and $10=$ superior quality.

At this time, pots containing amendment treatments were further divided into two groups, a drought stress and a control. Water was withheld in the drought stress group to allow soil dehydration. In each experiment, control plants for each treatment continued to receive water by replacing the daily water loss from transpiration $\left(\approx 4-5 \mathrm{~mm} \cdot \mathrm{d}^{-1}\right)$, but fertilization for all treatments was discontinued. Transpiration was measured by weighing the pots every afternoon at $\approx 1300$ HR. Daily transpiration was calculated as the difference in weight from that on the previous day. To minimize the daily effects of fluctuations in transpiration, data were normalized by dividing daily transpiration of turf in the stress treatment by daily mean transpiration of control plants for the same treatment. The daily ratio was further normalized by dividing the mean individual plant daily ratio by the average transpiration obtained between the first 2 to $4 \mathrm{~d}$ of the experiment, when all plants were well-watered (i.e., before differences between stressed plants and control plants began to develop) (Ray and Sinclair, 1997). The second normalization served to remove variation in transpiration rates among turf and was denoted as the normalized transpiration ratio (NTR) as defined in Eq. 1:

$\mathrm{NTR}=$

[daily wt loss (stressed)/daily wt loss of control]

avg daily transpiration rate for day $2-4$

This second normalization assured that all plants had an average NTR equal to 1 when adequate soil water was available.

Soil in pots was allowed to dry through transpirational water loss until plants showed signs of very severe water stress. At this point, plants had lost turgor and had begun to turn 
from a dark green to straw color. This corresponded to a NTR value below 0.12 , which was defined as the endpoint of the drying cycle (Sinclair and Ludlow, 1986). At the endpoint, the pot weight was recorded (=final pot weight). This time from the beginning of the drying cycle unit the day NTR value fell below 0.12 was designated as the days to wilt (DTW). The dehydration cycle usually required $\approx 2$ weeks. Turf was not clipped during the cycle because aboveground growth was minimal once the turf was moderately drought-stressed. The transpirable soil water (TSW) for each pot was calculated by difference as indicated in Eq. 2: TSW = initial pot weight - final pot weight

A daily fraction of transpirable soil water (FTSW) for each pot in the stress treatment was calculated using Eq. 3 (Ray and Sinclair, 1997).

Daily FTSW =

$\underline{\text { (pot wt on a specific day - final pot wt) }}$

$$
\text { transpirable soil water }
$$

This represents the stress level for each treatment expressed as a function of soil water content.

In each experiment, a single curve was generated for each treatment within each replication to determine the relationship between NTR and FTSW in response to a drying soil (Fig. 1) using the following exponential model:

$$
\mathrm{NTR}=\frac{\mathrm{A}}{1+\exp \frac{\left[-\left(\text { FTSW }-\mathrm{x}_{0}\right)\right]}{\mathrm{B}}}
$$

A similar model was reported by Muchow and Sinclair (1991) to determine crop gas exchange as a function of transpirable soil water in maize (Zea mays L.). Sinclair and Ludlow (1986) evaluated stomatal and epidermal conductance while comparing the relative transpiration rates with the fraction of transpirable soil water. Stomatal and epidermal conductance was determined through measurements using individual leaves from both well-watered plants and drought-stressed plants, using standard diffusion equations (Willis and Jefferies, 1963) from weight losses of detached leaflets measured under defined evaporative conditions in a chamber under controlled $\mathrm{CO}_{2}$ concentrations. The FTSW point at which NTR begins to decline was correlated with stomatal closure.

The fit of the curve generated was tested using the nonlinear regression procedures of SAS (SAS Institute, Inc., 1988) and an $\mathrm{r}^{2}$ value was computed for each curve. To determine the FTSW point at which stomata began to close, a segmented model for quadratic-plateau available in the PROC NLIN procedure (SAS Institute, 1985) was employed. Because of the double normalization used to calculate NTR, the plateau was constrained to equal 1.0. Comparisons among treatments for DTW, TSW, and the FTSW at which stomata began to close were made using least significant difference mean separations at $P \leq 0.05$. Differences in spring versus summer establishment resulted in experiment $\times$ amendment interactions, so means were analyzed separately for each experiment.

\section{Results and Discussion}

Six weeks after core aerification, best turf quality for both experiments was observed in ZeoPro amendment treatments (Table 1). Huang and Petrovic (1996) demonstrated that clinoptilotlite zeolite (ZeoPro) has a positive effect on turfgrass establishment, growth, and quality. ZeoPro exhibits selective retention of $\mathrm{NH}_{4}^{+}$and $\mathrm{K}^{+}$, which may provide added benefits for turf growth (Nus and Brauen, 1991). In Expt. 1, Profile, amendment and native soil were effective in producing high quality turfgrass, followed by amendments EcoSand, Ecolite, and Profile Fine. Axis, Greenschoice,
Isolite, PSA ${ }^{\circledR}$, sand, and sand + peat treatments produced turf below an acceptable quality level (Table 1). Quality ratings for turf growing in non-amended sand was poor (4.8), reflecting the difficulty in growing high-quality turf on a medium with poor nutrient and water retention.

Quality ratings for all treatments were greater in Expt. 2 than in Expt. 1, probably because of higher temperature and superior light quality during the summer establishment. Differences among the best performing treatments were marginal. Turf grown on nonamended sand and PSA treatments were the lowest in quality, but still above the minimally acceptable rating. Since water was not limiting at this stage of the experiments, differences among treatments were probably the result of physical differences in the root zone following amendment application and nutrient supply to the growing plant.

Amendments are added to sand to improve both nutrient and moisture retention (Beard, 1973). There were differences among treatments in the transpirable soil water (TSW) available to the plants (Table 1). The TSW estimates differ from the more commonly used available soil water estimates in that the lower limit is defined by the volumetric soil water content where the daily transpiration rate of drought-stressed plants becomes $<12 \%$ of wellwatered plants. The differences in the amount of soil water extracted from the pots (in the confined rooting volume) clearly indicated effects of the amendment on the amount of available water. The amended sand retained 10 to $128 \mathrm{~g}$ more transpirable soil water than did sand alone in Expt. 1 and 19 to $77 \mathrm{~g}$ more in Expt. 2. These increases translate into maximum increases of 6 and $4 \mathrm{~mm}$ of water for Expt. 1 and 2, respectively. The water-holding capacity of these amendments is particularly evident, considering that only $8.5 \%$ of the root zone volume was modified.

Under similar conditions in the greenhouse,

Table 1. Effects of soil amendments on turfgrass quality, average transpirable soil water (TSW), average number of days to the endpoint of the soil dehydration treatment, and fraction of transpirable soil water (FTSW) point at which stomatal closure begins to occur as estimated by plateau regression for two greenhouse

\begin{tabular}{|c|c|c|c|c|c|c|c|c|}
\hline \multirow[b]{2}{*}{ Treatment } & \multicolumn{4}{|c|}{ Expt. 1} & \multicolumn{4}{|c|}{ Expt. 2} \\
\hline & Quality & $\mathrm{TSW}^{\mathrm{z}}$ & Days to endpoint ${ }^{y}$ & FTSW $^{x}$ & Quality & TSW & Days to endpoint & FTSW \\
\hline & & --- g --- & --- d --- & & & --- g --- & --- d --- & \\
\hline Axis & $5.6 \mathrm{e}^{\mathrm{w}}$ & $898 \mathrm{ab}$ & $12.5 \mathrm{a}$ & $0.39 \mathrm{a}$ & $8.0 \mathrm{bc}$ & $865 \mathrm{a}$ & $13.8 \mathrm{a}$ & $0.42 \mathrm{a}$ \\
\hline Ecolite & $7.0 \mathrm{bc}$ & $843 \mathrm{c}-\mathrm{e}$ & $10.8 \mathrm{~d}$ & $0.28 \mathrm{~b}-\mathrm{f}$ & $8.2 \mathrm{~b}$ & $848 \mathrm{a}-\mathrm{c}$ & $13.5 \mathrm{a}$ & $0.34 \mathrm{a}-\mathrm{c}$ \\
\hline EcoSand & $7.2 \mathrm{bc}$ & $875 \mathrm{a}-\mathrm{e}$ & $11.2 \mathrm{~b}-\mathrm{d}$ & $0.24 \mathrm{ef}$ & $7.8 \mathrm{bc}$ & $817 \mathrm{a}-\mathrm{d}$ & $12.5 \mathrm{ab}$ & $0.39 \mathrm{ab}$ \\
\hline EcoSand X & $6.7 \mathrm{~cd}$ & $853 \mathrm{~b}-\mathrm{e}$ & $11.2 \mathrm{~b}-\mathrm{d}$ & $0.25 \mathrm{~d}-\mathrm{f}$ & $8.3 \mathrm{ab}$ & $843 \mathrm{a}-\mathrm{c}$ & $13.2 \mathrm{ab}$ & $0.24 \mathrm{bc}$ \\
\hline Greenschoice & $5.7 \mathrm{e}$ & 837 ef & $11.8 \mathrm{a}-\mathrm{c}$ & $0.34 \mathrm{bc}$ & $7.7 \mathrm{bc}$ & $838 \mathrm{a}-\mathrm{c}$ & $13.8 \mathrm{a}$ & $0.30 \mathrm{a}-\mathrm{c}$ \\
\hline Isolite & $5.8 \mathrm{e}$ & $890 \mathrm{a}-\mathrm{c}$ & $12.2 \mathrm{a}$ & $0.33 \mathrm{bc}$ & $7.5 \mathrm{bc}$ & $861 \mathrm{ab}$ & $13.8 \mathrm{a}$ & $0.34 \mathrm{a}-\mathrm{c}$ \\
\hline Native soil & $7.5 \mathrm{~b}$ & 839 de & $12.2 \mathrm{a}$ & $0.26 \mathrm{c}-\mathrm{f}$ & $7.3 \mathrm{bc}$ & $814 b-d$ & $13.0 \mathrm{ab}$ & $0.32 \mathrm{a}-\mathrm{c}$ \\
\hline Profile & $7.7 \mathrm{~b}$ & $908 \mathrm{a}$ & $11.8 \mathrm{a}-\mathrm{c}$ & 0.24 ef & $8.2 \mathrm{~b}$ & $844 a-c$ & $13.2 \mathrm{ab}$ & $0.43 \mathrm{a}$ \\
\hline Profile Fine & $7.0 \mathrm{bc}$ & $886 \mathrm{a}-\mathrm{d}$ & $11.5 \mathrm{a}-\mathrm{d}$ & $0.32 \mathrm{~b}-\mathrm{e}$ & $8.0 \mathrm{bc}$ & $821 \mathrm{a}-\mathrm{d}$ & $13.8 \mathrm{a}$ & $0.35 \mathrm{a}-\mathrm{c}$ \\
\hline PSA & $6.2 \mathrm{de}$ & $903 \mathrm{a}$ & $12.0 \mathrm{ab}$ & $0.28 \mathrm{~b}-\mathrm{f}$ & $7.0 \mathrm{c}$ & $854 \mathrm{a}-\mathrm{c}$ & $13.8 \mathrm{a}$ & $0.45 \mathrm{a}$ \\
\hline Sand & $4.8 \mathrm{f}$ & $780 \mathrm{~g}$ & $11.2 \mathrm{~b}-\mathrm{d}$ & $0.32 \mathrm{~b}-\mathrm{d}$ & $7.0 \mathrm{c}$ & $788 \mathrm{~d}$ & $12.0 \mathrm{bc}$ & $0.31 \mathrm{a}-\mathrm{c}$ \\
\hline Sand + Peat & $5.7 \mathrm{e}$ & $789 \mathrm{fg}$ & $11.8 \mathrm{a}-\mathrm{c}$ & $0.35 \mathrm{~b}$ & $7.3 \mathrm{bc}$ & $838 \mathrm{a}-\mathrm{c}$ & $13.5 \mathrm{a}$ & $0.35 \mathrm{a}-\mathrm{c}$ \\
\hline ZeoPro & $8.8 \mathrm{a}$ & $894 \mathrm{ab}$ & $11.0 \mathrm{~cd}$ & $0.12 \mathrm{~g}$ & $9.3 \mathrm{a}$ & $807 \mathrm{~cd}$ & $11.0 \mathrm{c}$ & $0.21 \mathrm{c}$ \\
\hline $\mathrm{LSD}_{0.05}$ & 0.8 & 49 & 0.8 & 0.08 & 1.0 & 49 & 1.4 & 0.17 \\
\hline $\mathrm{CV}(\%)$ & 10.5 & 3.9 & 5.1 & 18.7 & 11.9 & 4.1 & 7.6 & 34.5 \\
\hline
\end{tabular}
experiments rated 6 weeks after core aerification, taken on the same day soil dehydration cycles were initiated. Means represent average over six replications.

${ }^{\mathrm{z}}$ Transpirable soil water $=$ difference between initial and final pot weight.

yNo. of days water was withheld from each plant in the stress treatment until its normalized transpiration ratio value dropped below 0.12

${ }^{x}$ Fraction of transpirable soil water $=($ Pot weight on a specific day - final pot weight $) /$ transpirable soil water.

${ }^{\text {w} M e a n ~ s e p a r a t i o n ~ w i t h i n ~ c o l u m n s ~ b y ~ L S D ~ a t ~} P \leq 0.05$. 
the same plant genetic material should have the same ET rates under nonlimiting soil water. During soil water depletion, ET rates decline and drought stress symptoms become apparent (Aronson et al., 1987). Because the same grass was grown in each treatment, the number of days to reach the endpoint of the experiments $(\mathrm{NTR}=0.12)$ provided a useful comparison among the amendment treatments. The time to reach the endpoint is indicative of differences in absolute (non-normalized) water use rates of the same genetic material growing under different soil conditions. A longer time to the endpoint indicates a greater amount of water available to the plant or a lower rate of water use. Turf grown in the Axis, Isolite, and native soil treatments in Expt. 1 generally required more time to reach the endpoint than did most other treatments (Table 1). However, time to endpoint for these treatments was similar to those for Greenschoice, Profile, Profile Fine, PSA, and sand + peat treatments. The dry-down cycle took longer in Expt. 2 because ET rates (mean $=4 \mathrm{~mm} \cdot \mathrm{d}^{-1}$ ) were lower in the fall than in midsummer $\left(\right.$ mean $\left.=5 \mathrm{~mm} \cdot \mathrm{d}^{-1}\right)$. ZeoPro took fewer days to reach the endpoint than did all other treatments except sand; there was little separation among the remaining treatments. While sand took fewer days, it was similar to EcoSand, EcoSandX, native soil, and Profile. The performance of turf in the sand treatment is probably a result of its reduced TSW in relation to other treatments. This was not the case in the ZeoPro treatment. Turf grown in the nutrient-enriched ZeoPro had better quality (Table 1), appeared more succulent, and maintained a higher daily ET until it became drought stressed, than did turf in other treatments. Plants growing in ZeoPro-amended soil therefore extracted water from the pots more quickly than did those in other treatments, resulting in a shorter dry-down cycle. Carrow (1995) reported that high clipping dry weights and shoot density are associated with higher turfgrass ET rates when the turf is well irrigated, but under drier conditions, stomatal aspects and rooting characteristics strongly influence ET and, ultimately, drought avoidance.

A consistent relationship was found between NTR and FTSW for turfgrass grown in each soil treatment. The NTR vs. FTSW data were fitted to an exponential equation similar to that presented by Muchow and Sinclair (1991). The general trend was similar to that reported for maize by Ray and Sinclair (1997), as illustrated by data from Expt. 1 for the Axis amendment treatment (Fig. 1A) and the ZeoPro amendment treatment (Fig. 1B). The equation described the response of NTR very well ( $r^{2}$ of at least 0.95 for each treatment). In general, the NTR was equivalent to well-watered plants until FTSW decreased to roughly 0.3 to 0.4 . As FTSW decreased further, there was a nearly linear decline in NTR until FTSW equaled 0.

Plateau regression was used to focus specifically on the FTSW value at which the stomata began to close. Fig. $1 \mathrm{~A}$ and B include the plateau regression line as an example of the results obtained. The FTSW for the initiation

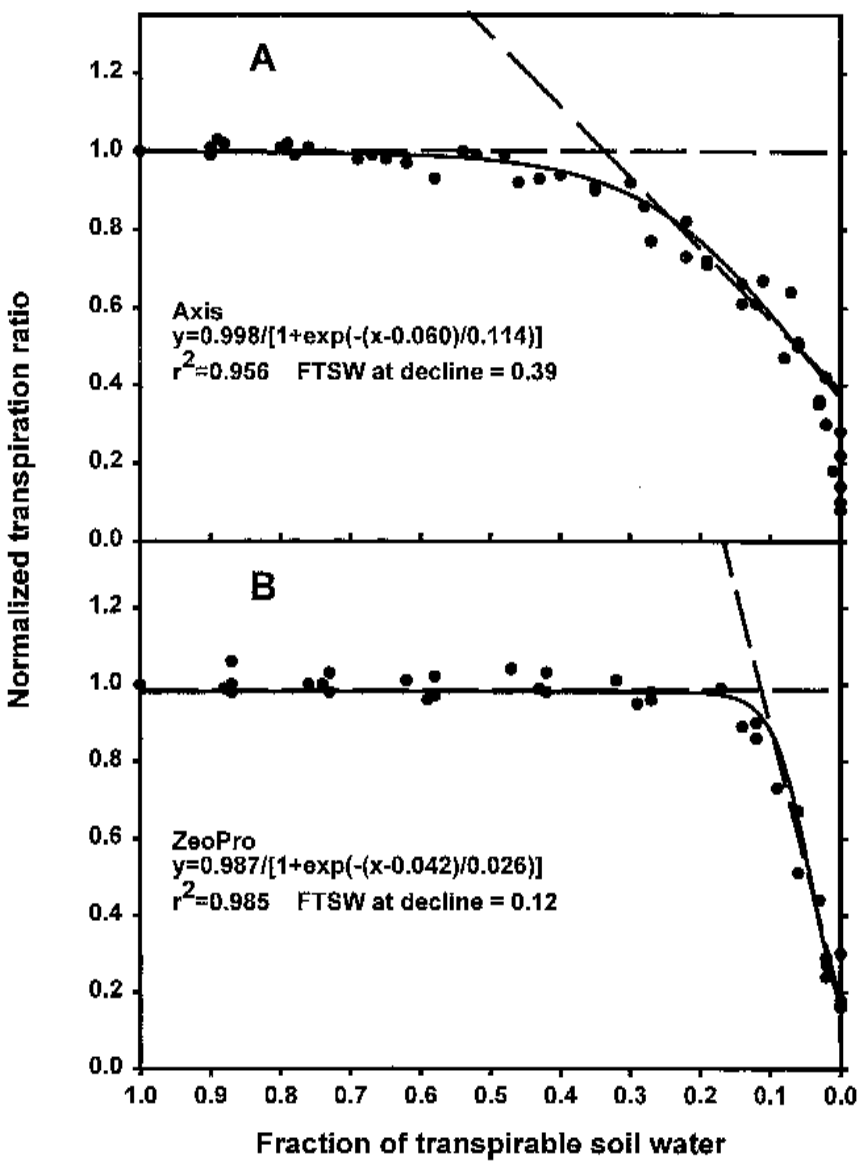

Fig. 1. Normalized transpiration ratio vs. fraction of transpirable soil water on each day of a soil drying cycle for sand amended with (A) Axis or (B) ZeoPro. Solid line is the regression fit to the data by means of an exponential model. The slanted, dashed line is the linear regression for the data during the stomatal closure phase obtained by plateau regression with the plateau constrained to be one. The intersection of the dashed lines indicates the point at which stomata began to close.

of stomatal closure was estimated by plateau regression for grass grown in each treatment (Table 1). Muchlow and Sinclair (1991) indicated that the relationship between FTSW and relative transpiration in maize was unaffected by soil type. In this study, plateau regression clearly distinguished the differences among soil treatments (Fig. 1). Since the same genetic material was used for all treatments, these results had to be due to differences in the root zone's water-holding capacity or to an alteration in the plant's growth due to availability of water and nutrients. Changes in root growth patterns may have accounted for some of the differences. Brar and Palazzo (1995) reported that soil texture affected turfgrass root depth, length, branching, and dry matter, and the root/shoot ratio.

In Expt. 1, turfgrass grown in ZeoPro closed its stomata at a much smaller FTSW value $(0.12)$ than did the turfgrass growing in other amendments $($ mean FTSW $=0.30)$ (Table 1$)$. Although not as clearly separated in Expt. 2, turfgrass grown in ZeoPro did begin to close its stomata at smaller FTSW values (0.21) than did that in other treatments (mean FTSW $=0.35$ ). The lower FTSW for stomatal closure means that the plant could extract additional soil water before stomatal closure, and thus would exhibit a comparatively higher transpi- ration rate for a longer period of time. This delayed closure of stomata would appear to be advantageous under drought conditions when the stress is short and intermittent. On the other hand, drought stress of long duration would favor stomata closing early in the drying cycle. This would conserve water and increase the plant's chance of survival (Ray and Sinclair, 1997). This was the case with turfgrass grown in Axis in Expt. 1 and to a lesser extent in Expt. 2 (Table 1). Plants that closed their stomata at higher FTSW generally had a higher average time to the endpoint in the soil drying cycle. The small differences among treatments in the NTR response to FTSW (largest FTSW difference $=0.27$ ) may well be the result of similarity among amendments, combined with the small percentage of the root zone that they occupied. Although the differences were small among amendments, the implications of these differences can be quite important, considering that total transpirable soil water in these pots was $\approx 45 \mathrm{~mm}$.

This study demonstrates that turfgrass may perform differently when grown in various inorganic root-zone media. These data suggest that inorganic soil amendments can influence soil water content, which may ultimately influence the plant's response to drought stress. Additional research is needed to quan- 
tify the influence these amendments have on turf physiological response when they occupy varying volumes in the root zone. Even in the small volumes tested in this study, several amendments enhanced turf quality and improved moisture status in comparison with sand.

\section{Literature Cited}

Aronson, L.J., A.J. Gold, and R.J. Hull. 1987. Coolseason turfgrass response to drought stress. Crop Sci. 27:1261-1266.

Beard, J.B. 1973. Turfgrass: Science and culture. Prentice-Hall, Englewood Cliffs, N.J.

Brar, G.S. and A.J. Palazzo. 1995. Shoot and root development of tall and hard fescues in two different soils. J. Environ. Qual. 24:777-781.

Carrow, R.N. 1995. Drought resistance aspects of turfgrasses in the southeast: Evapotranspiration and crop coefficients. Crop Sci. 35:1685-1690.

Huang, Z.T. and A.M. Petrovic. 1996. Clinoptilolite zeolite effect on evapotranspiration rate and shoot growth rate of creeping bentgrass on sand based greens. J. Turfgrass Mgt. 1(4):1-9.

Muchow, R.C. and T.R. Sinclair. 1991. Water deficit effects on maize yields modeled under current and "greenhouse" climates. Agron. J. 83:1052-1059.

Nus, J.L. and S.E. Brauen. 1991. Clinoptilolitic zeolite as an amendment for establishment of creeping bentgrass on sandy media. HortScience 26:117-119.

Ray, J.D. and T.R. Sinclair. 1997. Stomatal closure of maize hybrids in response to drying soil. Crop Sci. 37:803-807.

Ritchie, J.T. 1980. Climate and soil water, p. 1-24. In: L.S. Murphy, L.F. Welch, and E.C. Doll (eds.). Moving up the yield curve: Advances and obstacles. ASA Pub. No 39. Madison, Wis. SAS Institute, Inc. 1985. The NLIN procedure. SAS user's guide: Statistics. 5th ed. SAS Inst., Cary, N.C.

SAS Institute, Inc. 1988. SAS/STAT user's guide, release 6.03 edition. SAS Inst., Cary, N.C.

Sinclair, T.R. and M.M. Ludlow. 1986. Influence of soil water supply on the plant water balance of four tropical grain legumes. Austral. J. Plant Physiol. 13:329-341.

Weisz, R., J. Kaminski, and Z. Smilowitz. 1994. Water deficit effects on potato leaf growth and transpiration: Utilizing fraction extractable soil water for comparison with other crops. Amer. Potato J. 71:829-840.

Willis, A.J. and Jefferies, R.L. 1963. Investigations on the water relations of sand-dune plants under natural conditions, p. 169-189. In: The water relations of plants. A.J. Ruttera and F.H. Whitehead (eds.). Blackwells, Oxford, U.K. 